\title{
Priming complex words: Evidence for supralexical representation of morphology
}

\author{
HÉLÈNE GIRAUDO \\ Université de Provence, Aix-en-Provence, France \\ and \\ JONATHAN GRAINGER \\ CNRS and Université de Provence, Aix-en-Provence, France
}

\begin{abstract}
Effects of morphologically related primes were examined in two masked prime experiments. Responses to both free root and derived suffixed word targets were facilitated when primes were derived suffixed words containing the target's root, and this facilitation effect showed a time course similar to that for the facilitation effect of repetition primes (though systematically smaller in magnitude). In a control experiment only the longest prime duration of Experiment 1 was used; responses to derived suffixed word targets were facilitated by both free root primes and derived suffixed word primes sharing the target's root (relative to unrelated and form-related control primes). The free root and derived suffixed word prime conditions did not differ significantly. In Experiment 2, only true derived word primes produced facilitation, whereas morphologically simple primes containing a pseudoroot did not influence performance relative to the unrelated prime condition. We argue that this supports a supralexical account of morphological representation.
\end{abstract}

Morphologically complex words are words composed of at least two morphemes, such as the French word balay/eur (sweep/er). Although most researchers now agree that some form of morphological information is automatically retrieved during language comprehension (e.g., Drews \& Zwitserlood, 1995; Feldman, 1994; Frost, Forster, \& Deutsch, 1997; Grainger, Colé, \& Segui, 1991; Laudanna, Badecker, \& Caramazza, 1992; Marslen-Wilson, Komisarjevsky-Tyler, Waksler, \& Older, 1994), there is little agreement about how this occurs. In order to solve this problem, one must first specify how morphological information is stored in long-term memory. We will discuss two main alternatives here that differ in terms of where, in the processing hierarchy from form to meaning, morphological codes are situated. According to the sublexical hypothesis, morphological representations are contacted before whole-word representations. ${ }^{1}$ In this view, a given word stimulus is parsed into its morphological components before the word can be recognized as a whole (Taft, 1994; Taft \& Forster, 1975). According to the supralexical hypothesis, morphological representations are contacted after whole-word representations. On presentation of a complex word such as remake, units corresponding to the root make and the affix re will receive

The authors thank three anonymous reviewers and the action editor Ken Forster for their constructive criticism of an earlier version of this work. The first author was supported by a doctoral fellowship "cognisciences" from the French Ministry of Education. Correspondence concerning this work can be addressed to H. Giraudo, CIRLEP, Université de Reims, Campus Croix Rouge, 57 Rue Taittinger F-51096 Reims (email:helene.giraudo@univ-reims.fr). activation from the whole-word representation and send back activation to all whole-word representations that are compatible with either the root or the affix. In this way, root representations impose an organization on the lower level form representations in terms of "morphological families" (Butterworth, 1983; Lukatela, Gligorijević, Kostić, \& Turvey, 1980; Manelis \& Tharp, 1977).

In our first experiment, we compared morphological priming effects on lexical decision latencies to simple and complex word targets, using primes that were either free roots or derived suffixed words. If a complex word is first parsed into its constituent morphemes (the sublexical hypothesis), then in the masked prime paradigm with brief prime exposures, root primes should be more effective than derived word primes, since the former do not require parsing. Here the basic assumption is that there is some extra computation involved in isolating a root in a derived word in comparison with recognizing a root presented on its own. ${ }^{2}$ This extra computation should slow down the processing of derived word primes, leading to less priming. On the other hand, according to the supralexical hypothesis, derived word primes should be just as effective as root primes. Both types of prime will lead to similar levels of preactivation of supralexical morphological units. The bi-directional excitatory links between a supralexical representation of the root and all words containing that root will facilitate the recognition of a target word sharing the same root as the prime.

More precisely, the sublexical hypothesis predicts that priming from derived words should appear with longer prime exposures than those required for significant priming from roots. In order to test this, in Experiment 1 we 
used the incremental priming technique (Jacobs, Grainger, \& Ferrand, 1995), wherein prime presentation duration and/or intensity is varied within participants. As with the masked prime paradigm (Forster \& Davis, 1984), the range of prime exposures is such that participants generally do not report having identified any prime stimuli.

\section{EXPERIMENT 1}

\section{Method}

Participants. Forty psychology students at the University of Provence participated in the experiment. In this and the following experiment, all participants were native speakers of French who reported normal or corrected-to-normal vision.

Design and Stimuli. Forty free roots and forty derived suffixed words in French were selected, defining the target type factor. Derived suffixed word targets were primed by (1) the same word (e.g., balayage-balayage), (2) the free root of the target (e.g., balaibalayage ), (3) a derived suffixed word sharing the same root morpheme (e.g., balayeur-balayage), and (4) an unrelated morphologically simple word (e.g., guitare-balayage). Root targets were primed by (1) the same word (e.g., balai-balai), (2) a derived suffixed word sharing the same root morpheme (e.g., balayage-balai), (3) another derived suffixed word sharing the same root morpheme (e.g., balayeur-balai), and (4) an unrelated word (e.g., guitare-balai). (Prime Condition 3 was of course identical to Prime Condition 2 when targets were free roots. This condition was included simply to have a balanced experimental design.) These conditions def ined the four levels of the prime type factor. Primes were on the average 6 letters long, and targets 5.8 letters long, and their average printed frequencies were 18 and 22 occurrences per million, respectively (Imbs, 1971). Eighty nonwords were constructed for the purposes of the lexical decision task. Forty of these were "morphologically simple" orthographically regular, pronounceable nonwords and forty were "complex" nonwords constructed by combining a real suffix to a string of letters that was not a root (e.g., banage where ban-was not a root and -age was a suffix in French). The nonword targets were tested in the same priming conditions as were the word targets. Prime- target pairings were counterbalanced across four experimental lists. Each participant was tested with the same list at each of five prime exposure durations $(0,14,29,42$, and $57 \mathrm{msec})$. Order of presentation of prime duration was counterbalanced using a Latin square design. Thus, all factors were manipulated within participants.

Procedure. Each trial consisted of the following sequence of three stimuli: A forward pattern mask composed of hash marks (\#) was presented for $500 \mathrm{msec}$, followed by the prime stimulus presented for a given duration $(0,14,29,43$ or $57 \mathrm{msec})$, which in turn was immediately replaced by the target string (word or nonword) that remained on the screen until participants responded. The primes were presented in uppercase and the targets in lowercase (with the necessary accents in French). The pattern mask was the same length as the prime word on each trial. The participants were instructed to respond as rapidly and accurately as possible whether the letter string in lowercase was or was not a French word. They responded "yes" by pressing one of two response buttons with the forefinger of their preferred hand and "no" by pressing the other response button with the forefinger of the other hand. The next trial followed after a 1-sec interval. The participants were not informed of the presence of prime words, and they received a set of 20 practice trials containing stimuli similar to those used in the main experiment.

\section{Results and Discussion}

Reaction times (RTs) lower than $300 \mathrm{msec}$ and exceeding $1,500 \mathrm{msec}$ were excluded from analysis $(0.6 \%$ of the data). Mean RTs and percent errors for each experimental condition are given in Table 1 . Analyses of variance (ANOVAs) by participants $\left(F_{1}\right)$ and items $\left(F_{2}\right)$ were performed on these data. There were significant main effects of prime type $\left[F_{1}(3,108)=25.31, p<.0001\right.$; $\left.F_{2}(3,234)=4.64, p<.005\right]$ and target type $\left[F_{1}(1,36)=\right.$ $\left.57.75, p<.0001 ; F_{2}(1,78)=24.76, p<.0001\right]$, but no effect of prime duration $\left[F_{1}<1 ; F_{2}(4,312)=1.50, p>\right.$ .10]. Target type did not interact with prime duration $\left[F_{1}(4,144)=1.22, p>.10 ; F_{2}<1\right]$ but significantly interacted with prime type in the analysis by participants

Table 1

Mean Reaction Times (in Milliseconds) and Percentage of Errors to Word Targets in Each Experimental Condition; Net Priming Effects Relative to the Unrelated Prime Condition Are Given for All Other Prime Conditions

\begin{tabular}{|c|c|c|c|c|c|c|c|c|c|c|}
\hline \multirow[b]{3}{*}{ Targets } & \multicolumn{10}{|c|}{ Prime Exposure Duration (msec) } \\
\hline & \multicolumn{2}{|c|}{0} & \multicolumn{2}{|c|}{14} & \multicolumn{2}{|c|}{29} & \multicolumn{2}{|c|}{43} & \multicolumn{2}{|c|}{57} \\
\hline & $M$ & $\mathrm{PE}$ & $M$ & $\mathrm{PE}$ & $M$ & $\mathrm{PE}$ & $M$ & $\mathrm{PE}$ & $M$ & $\mathrm{PE}$ \\
\hline \multicolumn{11}{|c|}{ Derived Suffixed Words (e.g., balayage) } \\
\hline Repetition primes (e.g., balayage) & 648 & 9.0 & 640 & 10.7 & 626 & 10.5 & 634 & 8.0 & 618 & 9.2 \\
\hline Root primes (e.g., balai) & 651 & 10.5 & 644 & 8.5 & 646 & 10.2 & 655 & 9.0 & 642 & 9.5 \\
\hline Derived primes (e.g., balayeur) & 646 & 10.0 & 648 & 10.2 & 639 & 9.2 & 649 & 10.5 & 628 & 10.0 \\
\hline Unrelated primes (e.g., guitare) & 638 & 10.5 & 641 & 10.7 & 648 & 10.0 & 672 & 10.2 & 660 & 11.7 \\
\hline Net effect, repetition & \multicolumn{2}{|c|}{-10} & \multicolumn{2}{|c|}{1} & \multicolumn{2}{|c|}{$22 *$} & \multicolumn{2}{|c|}{$38^{*}$} & \multicolumn{2}{|c|}{$42 *$} \\
\hline Net effect, root & \multicolumn{2}{|c|}{-13} & \multicolumn{2}{|c|}{-3} & \multicolumn{2}{|c|}{2} & \multicolumn{2}{|c|}{17} & \multicolumn{2}{|c|}{18} \\
\hline Net effect, derived & \multicolumn{2}{|c|}{-8} & \multicolumn{2}{|c|}{-7} & \multicolumn{2}{|c|}{9} & \multicolumn{2}{|c|}{$23 *$} & \multicolumn{2}{|c|}{$32 *$} \\
\hline \multicolumn{11}{|c|}{ Free Root (e.g., balai) } \\
\hline Repetition primes (e.g., balai) & 605 & 5.2 & 601 & 5.5 & 581 & 4.7 & 579 & 5.0 & 567 & 4.5 \\
\hline Derived primes 1 (e.g., balayage) & 603 & 7.2 & 605 & 6.7 & 602 & 5.2 & 604 & 6.0 & 609 & 3.5 \\
\hline Derived primes 2 (e.g., balayeur) & 590 & 7.5 & 610 & 5.7 & 598 & 6.0 & 606 & 3.5 & 606 & 5.0 \\
\hline Unrelated primes (e.g., guitare) & 609 & 5.7 & 617 & 5.7 & 618 & 8.5 & 638 & 8.0 & 635 & 6.5 \\
\hline Net effect, repetition & \multicolumn{2}{|c|}{4} & \multicolumn{2}{|c|}{16} & \multicolumn{2}{|c|}{$37 *$} & \multicolumn{2}{|c|}{$59^{*}$} & \multicolumn{2}{|c|}{$68 *$} \\
\hline Net effect, derived 1 & \multicolumn{2}{|c|}{6} & \multicolumn{2}{|c|}{12} & \multicolumn{2}{|c|}{$16^{*}$} & \multicolumn{2}{|c|}{$34 *$} & \multicolumn{2}{|c|}{$26^{*}$} \\
\hline Net effect, derived 2 & & 9 & & 7 & & & & $2 *$ & & \\
\hline
\end{tabular}

* Significant effects of repetition primes and morphologically related primes in comparison with the unrelated prime condition in the RT analysis ( $p<.05$ by participants and by items). 
$\left[F_{1}(3,108)=2.95, p<.05 ; F_{2}<1\right]$. Prime type significantly interacted with prime duration $\left[F_{1}(12,432)=5.96\right.$, $\left.p<.0001 ; F_{2}(12,936)=5.33, p<.0001\right]$. The triple interaction was not significant $\left(F_{1}<1 ; F_{2}<1\right)$, reflecting the fact that the prime type $\times$ prime duration interaction was significant for both types of target [root targets, $F_{1}(12,432)=4.81, p<.0001 ; F_{2}(12,468)=4.70$, $p<.0001$; derived suffixed targets, $F_{1}(12,432)=2.41$, $\left.p<.01 ; F_{2}(12,468)=2.03, p<.025\right]$.

The significant two-way interactions between prime type and prime duration reflect the steady increase of priming effects as a function of increasing prime exposure duration. Separate analyses of priming effects at each prime duration revealed significant effects at 29 , 43 , and $57 \mathrm{msec}\left(0 \mathrm{msec}, F_{1}<1, F_{2}<1 ; 14 \mathrm{msec}, F_{1}<1\right.$, $F_{2}<1 ; 29 \mathrm{msec}, F_{1}(3,108)=8.80, p<.00025 ; F_{2}(3,234)$ $=5.69, p<.0025 ; 43 \mathrm{msec}, F_{1}(3,108)=20.64, p<.0001$; $F_{2}(3,234)=7.29, p<.0005$; and $57 \mathrm{msec}, F_{1}(3,108)=$ $\left.23.44, p<.0001 ; F_{2}(3,234)=10.83, p<.0001\right]$. Significant differences (by participants and items using planned comparisons) between each prime condition and the unrelated prime condition are indicated in Table 1.

An analysis of the error rates showed no main effects or interactions. The nonword analysis showed no main effects or interactions, for RTs or for errors.

Contrary to the sublexical account of morphological representation, root primes (e.g., balai-balayage) did not generate faster RTs than did derived primes (e.g., balayeur-balayage). Indeed, as can be seen in Table 1, only derived word primes significantly facilitated target processing relative to unrelated controls at the longest prime duration. ${ }^{3}$ In the introduction, it was argued that isolating the root in a derived word would be computationally more costly (and therefore should take longer) than when the root was presented on its own. We were therefore led to predict the appearance of root priming effects before effects produced by derived words. This was clearly not the case.

The prediction of the sublexical hypothesis above would not hold, however, in a system that automatically activated a root representation as soon as the corresponding sequence of letters was detected, regardless of the letters that might either precede or follow that sequence. In such a system, a sublexical root representation would be activated whenever a sequence of letters corresponding to the orthographic description of that root was activated. This version of the sublexical hypothesis made one clear prediction to be tested in Experiment 2. Words containing a string of letters that corresponds to a real root (e.g., cost ...), but does not have the status of a root in that actual word (i.e., a pseudoroot, costume), should produce similar levels of priming as should true derived words (e.g., costly). The supralexical hypothesis predicted a significant advantage for derived word primes in comparison with pseudoroot primes, whereas the version of the sublexical hypothesis above predicted no difference between true derived words and words containing a pseudoroot.

\section{EXPERIMENT 2}

\section{Method}

Participants. Twenty-one psychology students at the University of Provence participated in the experiment.

Design and Stimuli. Thirty derived suffixed words were selected as targets. Each suffixed word target was primed by the following word primes: (1) a derived suffixed word sharing the same root (e.g., laitage-laitier); (2) a monomorphemic word containing a pseudo-root (e.g., laitue-laitier, where [lait-] in laitue does not constitute a root morpheme in French), and (3) an unrelated monomorphemic word (e.g., gorille-laitier). Targets and primes were matched overall in letter length (6.7 and 6.6 letters, respectively), and word targets and word primes were matched in printed frequency (22 and 19 occurrences per million, respectively; Imbs, 1971). Fifteen complex nonwords primed in exactly the same conditions as those for the target words were included in each experimental list. These nonwords, formed by the illegal combination of a root and a suffix (e.g., lait + iste), were primed by (1) a derived suffixed word sharing the same root as the target's (e.g., laitage-laitiste), (2) a monomorphemic word containing a pseudoroot (e.g., laitue-laitiste), and (3) an unrelated word (e.g., gorille-laitiste). Finally, 15 morphologically simple nonwords (i.e., not containing a possible root or affix) were added as filler stimuli and were primed by unrelated nonwords. Prime-target pairings were counterbalanced across three experimental lists. The participants received only one experimental list. Thus, participants were tested in all three priming conditions with a given target word being presented once.

Procedure. The procedure was the same as in Experiment 1, except that prime duration was fixed at $57 \mathrm{msec}$.

\section{Results \& Discussion}

RTs lower than $300 \mathrm{msec}$ and exceeding $1,500 \mathrm{msec}$ were excluded from analysis ( $0.6 \%$ of the data). Mean RTs and percent errors for each experimental condition are given in Table 2 . ANOVAs by participants $\left(F_{1}\right)$ and items $\left(F_{2}\right)$ were performed on these data. There was a main effect of prime type $\left[F_{1}(2,36)=16.54, p<.0001\right.$; $\left.F_{2}(2,58)=5.84, p<.01\right]$. Planned comparisons showed that morphological primes significantly facilitated target processing relative to both unrelated primes $\left[F_{1}(1,18)=\right.$ $\left.34.39, p<.001 ; F_{2}(1,29)=12.45, p<.0025\right]$ and pseudoroot primes $\left[F_{1}(1,18)=16.92, p<.001 ; F_{2}(1,29)=7.67\right.$, $p<.01]$. The pseudoroot priming condition did not differ significantly from the unrelated priming condition $\left[F_{1}(1,18)=1.61, p>.10 ; F_{2}<1\right]$.

No significant differences were observed in an analysis of the error rates to word targets, and the nonword analysis showed no significant effects for RTs or for errors.

Table 2

Mean Reaction Times (in Milliseconds), Percentage of Errors, and Net Priming Effects Relative to the Unrelated Prime Condition for the Derived Suffixed Word Targets (e.g., Laitier) in Each Experimental Condition of Experiment 2

\begin{tabular}{llrc}
\hline \multicolumn{1}{c}{ Prime Condition } & RT & PE & Net Effect \\
\hline Morphological(e.g., laitage) & 667 & 9.0 & $80^{*}$ \\
Pseudoroot (e.g., laitue) & 728 & 8.7 & 19 \\
Unrelated (e.g., gorille) & 747 & 12.7 & \\
\hline
\end{tabular}

* Significant priming effects relative to the unrelated condition in the RT analysis ( $p<.05$ by participants and by items). 
The results of Experiment 2 suggest that only true morphological primes facilitate target processing relative to unrelated primes. Pseudoroot primes did not facilitate the processing of derived suffixed words containing the same root. This particular result contradicts the predictions of the modified sublexical hypothesis (modified to accommodate the results of Experiment 1), while providing further support for the supralexical hypothesis. According to the modified sublexical hypothesis, a subset of letters corresponding to a potential root should activate the corresponding morphemic representation irrespective of the status of the other letters in the string. This should then lead to morphological priming from primes containing such sequences.

\section{GENERAL DISCUSSION}

The aim of the present study was to test two alternative accounts of the locus of morphological representations in a processing hierarchy that enables meaning to be derived from perceptual codes during normal automatic word recognition. The sublexical hypothesis situates morphemic representations below the level of whole-word orthographic or phonological representations, whereas the supralexical hypothesis situates these morphemic codes above the whole-word level. In the supralexical account, morphemic representations form a partial interface between whole-word form representations and the representation of meaning.

The predictions of the supralexical account were pitted against two versions of the sublexical account. In the first version, it was argued that morphologically complex words will be parsed into their corresponding morphemes before word recognition can be achieved. Since parsing a derived word involves isolating the root, and then checking that the remaining letters form a compatible affix, this should involve more computation than when a root is presented on its own (i.e., as a free root without an accompanying affix). The extra computation should delay the appearance of priming effects obtained from derived word primes in comparison with root primes. This was not observed in Experiment 1.

An alternative version of the sublexical hypothesis was tested in Experiment 2. According to this account, morphemic representations will be activated as soon as the appropriate string of letters is detected in the stimulus, regardless of the status of the remaining letters. This is an example of obligatory morphological decomposition where, at least in initial stages of processing, the system is blind to the compatibility of the morphological constituents. In this way, there will be no extra computation involved in processing a derived word prime, since no attempt will be made to check whether the remaining letters form an appropriate affix. This version of the sublexical hypothesis predicted that pseudoroot primes (word primes containing a string of letters corresponding to a root without having the status of a root in that par- ticular word) should be just as effective as true derived word primes. Experiment 2 demonstrated that this was not the case.

Significant morphological priming was obtained in the present experiments when both primes and targets were derived suffixed words (e.g., laitier-laitage). Using a cross-modal priming paradigm, Marslen-Wilson et al. (1994) failed to obtain any priming with suffixed English words, although significant priming was obtained when either the prime or the target was the stem, or when the derivational pairs were prefixed words. However, subsequent work (Marslen-Wilson, Zhou, \& Ford, 1996) suggests that the lack of priming for pairs of suffixed words in English is specific to auditory prime presentation. When primes are presented visually (in unmasked conditions), the effects of priming are reinstated and are therefore in line with those observed in the present study. Future research testing effects of masked visual primes on auditory targets should help clarify possible differences in the automatic processing of morphological information in different modalities.

\section{REFERENCES}

Butterworth, B. (1983). Lexical representation. Language Production, 2, 257-295.

Drews, E., \& Zwitserlood, P. (1995). Morphological and orthographic similarity in visual word recognition. Journal of Experimental Psychology: Human Perception \& Performance, 21, 1098-1116.

Feldman, L. B. (1994). Beyond orthography and phonology: Difference between inflections and derivations. Journal of Memory \& Language, 33, 442-470.

Forster, K. I., \& DAVIS, C. (1984). Repetition priming and frequency attenuation in lexical access. Journal of Experimental Psychology: Learning, Memory, \& Cognition, 10, 680-698.

Frost, R., Forster, K., \& Deutsch, A. (1997). What can we learn from the morphology of Hebrew? A masked priming investigation of morphological representation. Journal of Experimental Psychology: Learning, Memory, \& Cognition, 23, 1-28.

Grainger, J., Colé, P., \& Segui, J. (1991). Masked morphological priming in visual word recognition. Journal of Memory \& Language, 30, 370-384.

ImBS, P. (1971). Études statistiques sur le vocabulaire français: Dictionnaire des fréquences. Vocabulaire littéraire des XIXe et XXe siècles. Paris: Librairie Marcel Didier.

JACOBS, A. M., Grainger, J., \& Ferrand, L. (1995). The incremental priming technique: A method for determining within-condition priming effects. Perception \& Psychophysics, 57, 1101-1110.

Laudanna, A., Badecker, W., \& Caramazza, A. (1992). Processing inflectional and derivational morphology. Journal of Memory \& Language, 31, 333-348.

Lukatela, G., Gligorijević, B., Kostić, A., \& Turvey, M. T. (1980). Representation of inflected nouns in the internal lexicon. Memory \& Cognition, 8, 415-423.

Manelis, L., \& THARP, D. A. (1977). The processing of affixed words. Memory \& Cognition, 5, 690-695.

Marslen-Wilson, W., Komisarjevsky-Tyler, L., Waksler, R., \& OldER, L. (1994). Morphology and meaning in the English mental lexicon. Psychological Review, 101, 3-33.

Marslen-Wilson, W., Zhou, X., \& Ford, M. (1996). Morphology, modality, and lexical architecture. In G. Booij \& J. van Marle (Eds.), Yearbook of morphology. Amsterdam: Kluwer.

TAFT, M. (1994). Interactive-activation as a framework for understanding morphological processing. Language \& Cognitive Processes, 9 , 271-294. 
TAFT, M., \& Forster, K. I. (1975). Lexical storage and retrieval of prefixed words. Journal of Verbal Learning \& Verbal Behavior, 14, 638-647.

\section{NOTES}

1. In the term sublexical, "lexical" refers to the representation of wholeword orthographic and phonological forms.

2. In the introduction to Experiment 2, we will consider a version of the sublexical hypothesis wherein this assumption does not necessarily apply.

3 . The supralexical hypothesis predicts equivalent amounts of morphological priming from free root and derived word primes when these are matched for surface frequency. In support of this it should be noted that the 14-msec difference between root and derived primes at the 57msec prime duration was not statistically robust $\left[F_{1}(1,36)=2.08 ; F_{2}<1\right]$. As a further test of any potential difference between root and derived word primes, the stimuli of Experiment 1 (with the repetition primes re- placed by form related control primes; e.g., succes-sucrerie) were tested in a new experiment using a single prime exposure $(57 \mathrm{msec})$ with 48 new participants from the same population being presented with each target word once only. The design and procedure were otherwise identical to those of Experiment 1. The results were very clear. Mean RTs and percent errors (in parentheses) were 768 (10.2) for root primes, 766 (14.2) for derived suffixed primes, 795 (15.2) for orthographic control primes, and 798 (13.3) for unrelated control primes. Pairwise comparisons showed significant differences between the two morphological conditions and the two control conditions in the RT analysis (all $p s<.05$, by participants and items). In the error analysis, there were significant differences between root primes and the three other priming conditions that were not significant by items (all $p s<.05$, by participants).

(Manuscript received August 5, 1998;

revision accepted for publication February 9, 2000.) 